\title{
Very High Sputum Cyanide Concentrations during Acute Pulmonary Exacerbations in Cystic Fibrosis Patients
}

\section{Daniel Guck}

Pennsylvania State University

\section{David Kim}

Johns Hopkins University

\section{Brian Logue}

South Dakota State University

\section{Nesta Bortey-Sam}

South Dakota State University

\section{Nicole Tubbs}

Pennsylvania State University

\section{David Craft}

Pennsylvania State University

Philippe Haouzi ( $\sim$ phaouzi@pennstatehealth.psu.edu )

Pennsylvania State University

\section{Research Article}

Keywords: pseudomonas, pathogenesis, cyanide, exacerbation, cystic fibro

Posted Date: May 17th, 2021

DOl: https://doi.org/10.21203/rs.3.rs-465365/v1

License: (9) (i) This work is licensed under a Creative Commons Attribution 4.0 International License. Read Full License 


\section{VERY HIGH SPUTUM CYANIDE CONCENTRATIONS DURING ACUTE PULMONARY}

\section{EXACERBATIONS IN CYSTIC FIBROSIS PATIENTS}

Daniel Guck ${ }^{1}$, David Kim ${ }^{1}$, Nicole Tubbs ${ }^{1}$, Brian A. Logue ${ }^{2}$, Nesta Bortey-Sam², David Craft ${ }^{3}$, Philippe Haouzi ${ }^{1 *}$

${ }^{1}$ Division of Pulmonary and Critical Care Medicine, Department of Medicine Pennsylvania State University College of Medicine, Hershey, PA USA; ${ }^{2}$ Department of Chemistry and Biochemistry, South Dakota State University, Brookings, SD USA; ${ }^{3}$ Department of Microbiology, Pennsylvania State University College of Medicine, Hershey, PA USA

Keywords: pseudomonas, pathogenesis, cyanide, exacerbation, cystic fibro *Corresponding author: Philippe HAOUZI, MD, PhD. Division of Pulmonary and Critical Care Medicine, Department of Medicine, Pennsylvania State University, College of Medicine, 500 University Drive, H041, Hershey, PA 17033 phaouzi@pennstatehealth.psu.edu 
Background: Cyanide (CN) has been shown to be chronically present in the airways of cystic fibrosis (CF) patients, as a byproduct Pseudomonas' metabolism. We sought to determine the concentrations of $\mathrm{CN}$ in the sputum of CF patients, who were admitted to the hospital with acute clinical exacerbations.

Methods: Sputum was collected within 1 day (median) of admission and immediately analyzed for the presence of total and free $\mathrm{CN}$.

Results: We found 1) toxic levels of $\mathrm{CN}$ in the sputum of our patients, ranging from 27 to $401 \mu \mathrm{M}$, 2) the majority of the cyanide was in the form of free, thus diffusible, $\mathrm{CN}$ and 3) no cyanide in the blood.

Conclusions: While the chronic presence of $\mathrm{CN}$ in patients colonized with pseudomonas is not a new concept, the present data support the view that very high levels of free cyanide are present in the airways of CF patients during an acute clinical exacerbation, i.e. levels compatible with concentrations of $\mathrm{CN}$ able to virtually stop the mitochondrial activity. It becomes therefore urgent to investigate whether, in CF patients, cyanide is a significant factor affecting the short and long-term outcome and whether a specific treatment of $\mathrm{CN}$ intoxication of the airways is warranted during an exacerbation.

\section{Introduction}


Although the life expectancy of cystic fibrosis (CF) patients has steadily increased over the last 30 years, the current median survival of CF patients is still less than 40 years in the US [1, 2]. Current treatments aimed at restoring the function of the Cystic Fibrosis transmembrane conductance regulator (CFTR) are, unfortunately, not effective in every patient and must be used as early as possible to limit the development of irreversible structural lung damage. Therefore, the search for additional strategies aimed at impeding the development of airway remodeling and lung fibrosis must be pursued.

The pathophysiology of airway damage in CF is complex and multifarious. The lifelong persistence of microorganisms, e.g. staphylococcus pseudomonas, in the airways, which intensity worsens during acute episodes of clinical exacerbation, creates a pro-inflammatory microenvironment causing cellular dysfunction and destruction [3]. More specifically, the development of biofilms of pseudomonas aeruginosa, the most significant respiratory pathogen colonizing adult CF airways [4], is a significant contributor to the morbidity and mortality of this disease $[5,6]$; this contention is supported by a clear benefit of the use of high dosages of antibiotics aimed at lowering pseudomonas bacterial load during episodes of acute clinical exacerbations.

Pseudomonas can exert its toxicity through various mechanisms, one of them, which role has been overlooked, is the production of cyanide $(C N)[7,8]$. In a study published in 2008 , Ryall et al [5] found $\mathrm{CN}$ in the sputum of CF patients colonized by pseudomonas at an average concentration of $72 \mu \mathrm{M}$. Hydrogen cyanide can also been identified in the expired gas of young CF patients colonized with pseudomonas [9]. Furthermore, other bacteria such as Burkholderia cepacia, a common colonizer of the CF airways, can also produce cyanide [10]. If in free form, 
such concentrations of $\mathrm{CN}$ are well above levels capable of intoxicating cells [11] by inhibiting the mitochondrial respiratory chain [12-14]. For Instance, as reviewed by Cooper and Brown[15], cellular respiration is impeded in vitro by concentrations of free $\mathrm{CN}$ between 10-50 $\mu \mathrm{M}$, concentrations that are much lower than local concentrations present in the airways of CF patients. This toxicity may in turn affect any cell in the vicinity of the biofilm, inhibiting critical cellular functions, i.e. from ciliary activity [16] to endothelial or smooth muscles, leading to cellular dysfunction, and eventually tissue necrosis [13], unless significant tolerance develops. In addition, $\mathrm{CN}$ intoxication is always associated with a deleterious increase in reactive oxygen species production [17]. Based on these findings, it has been hypothesized that cyanide generation could per se be a significant contributor to pseudomonas aeruginosa pathogenicity in CF patients [18]. It is not known, however, whether cyanide is independently associated with worsening lung function [5] and promotion of disease progression [12].

The aim of our study was to determine cyanide levels in the sputum of CF patients admitted in hospital with symptoms of acute clinical exacerbation. The latter was defined as at least one of the following symptoms: increase in cough and sputum production, shortness of breath, fever, or hemoptysis. Previous studies have looked at cyanide levels in an outpatient setting [19] or in patients whose criteria for recruitment was to be actively colonized by Pseudomonas [5]. Our rationale was that since pseudomonas aeruginosa can produce cyanide levels upwards of 300-500 $\mu \mathrm{M}$ in vitro [4, 20], much higher levels of $\mathrm{CN}$ than those previously reported may be well present in the airways during acute clinical exacerbations, wherein bacterial load is increased. Second, we wanted to determine whether the pool of cyanide present in the sputum of these patients was in a free/diffusible form. Indeed, as protein or iron-bound 
cyanide would be virtually trapped in the sputum, their presence, even at very high concentrations, may not result in a noxious effect, per se. In contrast, free cyanide could diffuse outside the biofilm and cause significant cellular damage in the bacterium's vicinity. Finally, we determined the level of $\mathrm{CN}$ in the blood of few of these patients, although the very small amount of $\mathrm{CN}$ diffusing in the blood, if any, is expected to be rapidly metabolized [21]. Our objective was to expand our current knowledge on the presence of $\mathrm{CN}$ in $\mathrm{CF}$ patients during acute clinical exacerbations. 


\section{Methods}

Human sputum and blood collection

Thirteen adult CF patients were recruited during their admission to the Penn State Milton S. Hershey Medical Center during an acute clinical exacerbation (Table 1). Subjects had a median age 35 years (range 23-48). Their $\mathrm{FEV}_{1}$ averaged $39 \pm 16.7 \%$ of expected values, with a mean admission days per year of 28, a mean BMI of $23 \mathrm{~kg} / \mathrm{m}^{2}$, and a mean CF-ABLE score of 3 [22].

Subjects were admitted to the hospital for acute exacerbations of their CF, commonly reporting increasing cough and fatigue (see Table 1). Subjects were approached typically within 1 day of admission, as to decrease the amount of time subjects were exposed to antibiotics as part of their standardized treatment algorithm. Informed consent was obtained from each patient and the study was approved by the Hershey Medical Center/Penn State University Institutional Review Board Committee. Culture and identification of bacteria found in patient's sputa was performed by the Clinical Microbiology laboratory at Penn State Milton S. Hershey Medical Center using a standardized protocol for Cystic Fibrosis culture [23]. All methods were carried out in accordance with relevant guidelines and regulations

Sputum was collected in the morning after administration of hypertonic saline nebulizers (as an aid for sputum expectoration), aliquoted into sterile containers for the clinical microbiology lab and the analytical lab, and transported to the laboratories for immediate analysis. Sputum was weighed and half was flash frozen using liquid nitrogen for further analysis. In addition, sputa specimens were processed, inoculated and incubated in $\mathrm{CO}_{2}$ at $35^{\circ} \mathrm{C}$ for 4 days on the following media: Sheep Blood Agar, Chocolate Agar, Colistin-Nalidixic Acid Agar, MacConkey Agar, Mannitol Salt Agar, and Pseudomonas cepacia Agar. Bacterial identification 
was performed by matrix-assisted laser desorption ionization time-of-flight (MALDI-TOF) mass spectrometry (Bruker Daltonics, Hamburg, DE).

The treatment strategy for the patients CF exacerbation included antibiotic therapy, chest physiotherapy, mucolytics (Dornase alpha), and airway surface liquid hydrators such as nebulized hypertonic saline [24].

\section{Total CN measurement}

Total cyanide was measured using the approach proposed by Lundquist and Sörbo [25]. Sputum was diluted with one $\mathrm{ml}$ saline and vortexed. $1 \mathrm{~mL}$ of this mixture was added to $3 \mathrm{~mL}$ of $0.33 \mathrm{~mol} / \mathrm{L}$ perchloric acid and vortexed. After 2 minutes, the solution was centrifuged (Eppendorf, Hamburg, Germany) at 5000 rpm for 3 minutes and then filtered through glass wool in a Pasteur pipette. $2.5 \mathrm{~mL}$ of the filtrate was mixed with $500 \mu \mathrm{L}$ of $1.0 \mathrm{~mol} / \mathrm{L}$ sodium acetate before being mixed with $150 \mu \mathrm{L}$ of $0.05 \mathrm{~mol} / \mathrm{L}$ sodium hypochlorite. Within one minute, $500 \mu \mathrm{L}$ of barbituric acid-pyridine reagent was added and mixed. After 5-10 minutes, a BioSpectrometer (Eppendorf, Hamburg, Germany) was used to determine spectrum of absorbance of a $2 \mathrm{~mL}$ sample between 300 and $750 \mathrm{~nm}$ ). The absorbance at $580 \mathrm{~nm}$ was proportional to $\mathrm{CN}$ concentration. Negative control and positive controls were made using the same methodology with $1 \mathrm{~mL}$ saline and $100 \mu \mathrm{L} C N$. Standardized curves were established for CN using concentrations of $0,25,50,75$, and $100 \mu \mathrm{M}$.

Blood samples were obtained on the same day as sputum collection with a K2-EDTA vacutainer. The same approach was used to determine the concentration of CN in the blood [25]. 


\section{Cyanalyzer method for Free and Total CN in blood and sputum}

The concentrations of free and total $\mathrm{CN}$ in blood and sputum from CF patients were measured based on method described previously [26] with slight modifications. Briefly, whole blood or diluted sputum ( $25 \mu \mathrm{L}$; sputum was diluted by weighing $\approx 1 \mathrm{~g}$ of sputum and adding $3 \mathrm{~mL}$ of deionized water) was pipetted into the sample chamber of a sampling device, to which $80 \mu \mathrm{L}$ of deionized water was added. For free $\mathrm{CN}$ analysis, $200 \mu \mathrm{L}$ each of $\mathrm{NaOH}(0.1 \mathrm{M}), \mathrm{NDA}(0.002 \mathrm{M})$, and taurine $(0.1 \mathrm{M})$ were added to the capture chamber of the sampling device. Free $\mathrm{CN}$ (as HCN) in the sample was then transferred from the sample chamber to the capture chamber using active microdiffusion with room air as the carrier gas. The free $\mathrm{CN}$ was captured in the basic solution of the capture chamber as $\mathrm{CN}$ - and reacted with NDA and taurine to form a CN-NDAtaurine complex. The fluorescence signal of the CN-NDA-taurine complex was measured using the Cyanalyzer (a CN measuring device based on the core concepts of Jackson et al. 2014) [26].

For total $\mathrm{CN}$ analysis, the same procedure was followed for the analysis of free $\mathrm{CN}$, except $\mathrm{H}_{2} \mathrm{SO}_{4}(200 \mu \mathrm{L}$ of $2 \mathrm{M}$ ) was added to the sample in the sample chamber to convert all cyanide in the sample to $\mathrm{HCN}$. The $\mathrm{HCN}$ produced from the addition of $\mathrm{H}_{2} \mathrm{SO}_{4}$ was actively diffused to the capture chamber and reacted with NDA and taurine to form the CN-NDA-taurine complex. The

fluorescence signal was then measured using the Cyanalyzer. The fluorescence signals obtained from the blood or sputum samples were converted to concentrations using a calibration curve from $10-200 \mu \mathrm{M}$ CN.

\section{Spirometry measurement}


$\mathrm{FEV}_{1}$ was determined on the day after admission (spirometer Vyaire, California, USA). All spirometry measurements were done and interpreted according the American Thoracic Society recommendations [27].

Data analysis

Data are expressed as mean \pm SD, unless stated otherwise. Correlations were established between $[\mathrm{CN}]$ and patient characteristics (Age, BMI, admission days, $\mathrm{FEV}_{1}$, and CF-ABLE) using Microsoft Excel software. 


\section{Results}

\section{Total CN measurement}

Pseudomonas aeruginosa was isolated in twelve out of the thirteen patients. Total cyanide, analyzed by spectrophotometry, was however present in every sputum sample, with a concentration ranging from 27 to $401 \mu \mathrm{M}$ (average of $153 \pm 125 \mu \mathrm{M}$, Figure 1). We found no correlation between $[\mathrm{CN}]$ and age, $\mathrm{FEV}_{1}$, admission days in previous year, $\mathrm{BMI}$, or CF-ABLE scores. Of note, the seven patients with the highest $[\mathrm{CN}](>100 \mu \mathrm{M})$ had a similar FEV $\mathrm{F}_{1}$ and $\mathrm{CF}$-able score than those with low CN.

Free vs total CN measurement

The concentration of free and total cyanide in sputum was determined in 4 patients (samples 10 to 13, Table 2). Virtually all the CN present in the sputum samples was in free form (95 $\pm 17 \%$ of total $\mathrm{CN}$, Table 2 ) averaging $40.4 \pm 7.3 \mu \mathrm{M}$. Of note, the concentration of total $\mathrm{CN}$ was in a similar range (44 $\pm 13.2 \mu \mathrm{M})$, although lower, than the concentration obtained with spectrophotometry $(70 \pm 24 \mu \mathrm{M})$, which is likely due to possible loss of $\mathrm{CN}$ through transportation of sputum samples. Finally, we found no measurable cyanide in the blood samples (10 to 13) by either of the 2 methods.

\section{Discussion}

This study shows that in the sputum of CF patients with an acute clinical exacerbation, cyanide can be present at very high concentrations, i.e. at levels that were clearly in the toxic range [14]. This study confirms and expands the findings from Ryall et al [5], who, using an ion- 
sensing electrode, found up to $130 \mu \mathrm{M}$ of $\mathrm{CN}$ (average $72 \mu \mathrm{M}$ ) in the sputum of 15 patients with bronchiectasis colonized with pseudomonas, but who had no evidence of clinical exacerbation. Of interest, just like in our present results, there was no correlation between the level of $\mathrm{CN}$ and the deterioration in lung function in that study. They also found that cyanide was undetectable in 10 patients with significant structural damage but no pseudomonas infection. Recently, Eiserich et al [19] found sputum $\mathrm{CN}$ concentrations ranging from 14.1-98.1 $\mu \mathrm{M}$ in 12 cystic fibrosis patients who presented in an outpatient setting. Our patients displayed higher CN concentrations (averaging $153 \mu \mathrm{M}$ ), but were all presenting a clinical picture of CF exacerbation. Of note, in vitro, concentrations of free $\mathrm{CN}$ of less than $1 \mu \mathrm{M}$ are sufficient to literally stop the cytochrome c activity [15]. Since acute clinical exacerbations are typically associated with an increased bacterial load, an exaggerated cyanogenesis in the airways is not unexpected. This contention is supported by the decrease by half of $\mathrm{CN}$ concentration in the lungs of a mouse model with pseudomonas infection after few hours into antibiotic treatment [28]. Finally, one patient displayed significant concentrations of $\mathrm{CN}$ in the sputum while no pseudomonas could be isolated. As Achromobacter, the main bacterium in this patient, does not produce cyanide [29], we speculated that the isolated sputum culture that was obtained in this patient may not be representative of the airway microbiome. Pseudomonas was nevertheless found in this patient's airway a few months prior to and after this acute exacerbation.

An important finding of this study is that the vast majority of $\mathrm{CN}$ in the sputum was in the form of free $\mathrm{CN}$, which would be capable of diffusing into surrounding cells and blocking cytochrome C oxidase activity. This finding supports the view that $\mathrm{CN}$ found in the sputum of our patient is likely to be toxic for any cells in contact with the biofilm and the sputum but also in the 
alveolar regions, wherein free $\mathrm{CN}$ can diffuse as $\mathrm{HCN}$ [9]. As rhodanese activity -the major enzymatic system inactivating $\mathrm{CN}$ into thiocyanate [21] - is lower in the lung parenchyma than in other tissues [30], the presence of such high levels of cyanide could be especially toxic to lung structures. Of note, cyanide was undetectable in the blood, indicating that although free cyanide is present in the sputum, both the quantity of $\mathrm{CN}$ capable of diffusing and the capacity of the body to metabolize $\mathrm{CN}$ made it unlikely for $\mathrm{CN}$ to be found in the blood or tissues. Therefore, despite the lack of measurable $\mathrm{CN}$ in the bloodstream, we cannot rule out that some systemic effects could have been produced by the diffusion of cyanide from the alveolar regions into the blood.

Whether $\mathrm{CN}$ could be used as a marker of an acute exacerbation in a given patient has already been discussed and debated [12]. The very large range of $\mathrm{CN}$ found among patients in our study and its lack of correlation with the respiratory function challenge the idea that CN could be used as a good surrogate to evaluate the respiratory status. More importantly, whether cyanide could play, by itself, a significant contribution to clinical exacerbation episodes and to the development of irreversible lung and airway damage has fundamental therapeutic implications. Indeed, various ways of sequestering $\mathrm{CN}$ are currently used to treat systemic $\mathrm{CN}$ intoxication [31]. Some of these antidotes could be offered to rapidly decrease free $\mathrm{CN}$ in the airways of patients presenting with acute clinical exacerbations, with the goal of bringing $\mathrm{CN}$ concentrations toward less concerning levels. Two outstanding questions remain to be clarified: first, the capacity of the airway epithelium to metabolize cyanide or to trap it in the proteins present the sputum following chronic exposure is not known and could render the presence of $\mathrm{CN}$ in the airway less toxic than in naïve subjects. In other words, we have no clear idea if the 
chronic presence of cyanide in the airways should be a source of concern in these patients. secondly, the chronic presence of $\mathrm{CN}$ could also play a protective role by impeded fungal growth [32]. In the context of potential beneficial effects of $\mathrm{CN}$, the treatment of the persistent presence of low levels of $\mathrm{CN}$ in the lungs is therefore open to debate.

During an acute exacerbation, the benefit of providing systemic or inhaled cyanide binding agents, in addition to the current standard treatment, should be seriously evaluated in CF patients. 


\section{Declarations}

Ethics approval and consent to participate

Informed consent was obtained from each patient and the study was approved by the Hershey Medical Center/Penn State University Institutional Review Board Committee.

Consent for publication

NOT APPLICABLE

Availability of data and materials

All data generated or analysed during this study are included in this published article.

Competing interests

The authors have no conflict of interest or competing interests

\section{Funding}

The authors of this study were supported in part by a grant from the National Institute of Health, Counter-ACT Program R21NS098991.

\section{Authors' contributions}

Daniel Guck, David Kim and Nicole Tubbs collected the sputum samples and performed the analysis. Daniel Guck, David Kim made the figure and wrote the first draft of result and method sections, reviewed and edited the final version.

Brian Logue, Nesta Bortey-Sam, David Craft performed some of the analysis and edited the paper Philippe Haouzi conceived the study and wrote the first draft of the paper, he made the figure and reviewed and edited the final version of the manuscript

Acknowledgments

$N / A$ 
References

\section{Uncategorized References}

1. Elborn JS. Cystic fibrosis. Lancet. 2016;388(10059):2519-31. Epub 2016/05/04. doi: 10.1016/S0140-6736(16)00576-6. PubMed PMID: 27140670.

2. MacKenzie T, Gifford AH, Sabadosa KA, Quinton HB, Knapp EA, Goss CH, et al. Longevity of patients with cystic fibrosis in 2000 to 2010 and beyond: survival analysis of the Cystic Fibrosis Foundation patient registry. Ann Intern Med. 2014;161(4):233-41. Epub 2014/08/19. doi: 10.7326/M13-0636. PubMed PMID: 25133359; PubMed Central PMCID: PMCPMC4687404.

3. Cohen TS, Prince A. Cystic fibrosis: a mucosal immunodeficiency syndrome. Nat Med. 2012;18(4):509-19. Epub 2012/04/07. doi: 10.1038/nm.2715. PubMed PMID: 22481418; PubMed Central PMCID: PMCPMC3577071.

4. Williams HD, Zlosnik JE, Ryall B. Oxygen, cyanide and energy generation in the cystic fibrosis pathogen Pseudomonas aeruginosa. Adv Microb Physiol. 2007;52:1-71. Epub 2006/10/10. doi: 10.1016/S0065-2911(06)52001-6. PubMed PMID: 17027370.

5. Ryall B, Davies JC, Wilson R, Shoemark A, Williams HD. Pseudomonas aeruginosa, cyanide accumulation and lung function in CF and non-CF bronchiectasis patients. Eur Respir J. 2008;32(3):740-7. Epub 2008/05/16. doi: 10.1183/09031936.00159607. PubMed PMID: 18480102.

6. Wilson CB, Jones PW, O'Leary CJ, Hansell DM, Cole PJ, Wilson R. Effect of sputum bacteriology on the quality of life of patients with bronchiectasis. Eur Respir J. 1997;10(8):175460. Epub 1997/08/01. PubMed PMID: 9272915.

7. Cody WL, Pritchett CL, Jones AK, Carterson AJ, Jackson D, Frisk A, et al. Pseudomonas aeruginosa AlgR controls cyanide production in an AlgZ-dependent manner. J Bacteriol. 2009;191(9):2993-3002. Epub 2009/03/10. doi: 10.1128/JB.01156-08. PubMed PMID: 19270096; PubMed Central PMCID: PMCPMC2681793.

8. Gallagher LA, Manoil C. Pseudomonas aeruginosa PAO1 kills Caenorhabditis elegans by cyanide poisoning. J Bacteriol. 2001;183(21):6207-14. Epub 2001/10/10. doi: 10.1128/JB.183.21.6207-6214.2001. PubMed PMID: 11591663; PubMed Central PMCID: PMCPMC100099.

9. Gilchrist FJ, Belcher J, Jones AM, Smith D, Smyth AR, Southern KW, et al. Exhaled breath hydrogen cyanide as a marker of early Pseudomonas aeruginosa infection in children with cystic fibrosis. ERJ Open Res. 2015;1(2). Epub 2016/10/13. doi: 10.1183/23120541.000442015. PubMed PMID: 27730156; PubMed Central PMCID: PMCPMC5005121.

10. Ryall B, Lee X, Zlosnik JE, Hoshino S, Williams HD. Bacteria of the Burkholderia cepacia complex are cyanogenic under biofilm and colonial growth conditions. BMC Microbiol. 2008;8:108. Epub 2008/07/01. doi: 10.1186/1471-2180-8-108. PubMed PMID: 18588687; PubMed Central PMCID: PMCPMC2504479.

11. Baud FJ, Borron SW, Bavoux E, Astier A, Hoffman JR. Relation between plasma lactate and blood cyanide concentrations in acute cyanide poisoning. BMJ. 1996;312(7022):26-7. PubMed PMID: 8555853; PubMed Central PMCID: PMCPMC2349679.

12. Anderson RD, Roddam LF, Bettiol S, Sanderson K, Reid DW. Biosignificance of bacterial cyanogenesis in the CF lung. J Cyst Fibros. 2010;9(3):158-64. Epub 2010/02/17. doi: 10.1016/j.jcf.2009.12.003. PubMed PMID: 20156704.

13. Beasley DM, Glass WI. Cyanide poisoning: pathophysiology and treatment recommendations. Occup Med (Lond). 1998;48(7):427-31. Epub 1999/02/20. PubMed PMID: 10024740. 
14. Ball EG, Cooper O. The reaction of cytochrome oxidase with cyanide. J Biol Chem. 1952;198(2):629-38. PubMed PMID: 12999779.

15. Cooper CE, Brown GC. The inhibition of mitochondrial cytochrome oxidase by the gases carbon monoxide, nitric oxide, hydrogen cyanide and hydrogen sulfide: chemical mechanism and physiological significance. J Bioenerg Biomembr. 2008;40(5):533-9. doi: 10.1007/s10863008-9166-6. PubMed PMID: 18839291.

16. Nair C, Shoemark A, Chan M, Ollosson S, Dixon M, Hogg C, et al. Cyanide levels found in infected cystic fibrosis sputum inhibit airway ciliary function. Eur Respir J. 2014;44(5):125361. Epub 2014/09/05. doi: 10.1183/09031936.00097014. PubMed PMID: 25186256.

17. Cheung JY, Wang J, Zhang XQ, Song J, Tomar D, Madesh M, et al. Methylene blue counteracts cyanide cardiotoxicity: cellular mechanisms. J Appl Physiol (1985).

2018;124(5):1164-76. Epub 2018/02/09. doi: 10.1152/japplphysiol.00967.2017. PubMed PMID: 29420146; PubMed Central PMCID: PMCPMC6050200.

18. Winstanley $\mathrm{C}$, Fothergill JL. The role of quorum sensing in chronic cystic fibrosis Pseudomonas aeruginosa infections. FEMS Microbiol Lett. 2009;290(1):1-9. Epub 2008/11/20. doi: 10.1111/j.1574-6968.2008.01394.x. PubMed PMID: 19016870.

19. Eiserich JP, Ott SP, Kadir T, Morrissey BM, Hayakawa KA, La Merrill MA, et al. Quantitative assessment of cyanide in cystic fibrosis sputum and its oxidative catabolism by hypochlorous acid. Free Radic Biol Med. 2018;129:146-54. Epub 2018/09/15. doi:

10.1016/j.freeradbiomed.2018.09.007. PubMed PMID: 30213640.

20. Blumer C, Haas D. Mechanism, regulation, and ecological role of bacterial cyanide biosynthesis. Arch Microbiol. 2000;173(3):170-7. Epub 2000/04/14. PubMed PMID: 10763748.

21. Petrikovics I, Budai M, Baskin SI, Rockwood GA, Childress J, Budai L, et al.

Characterization of liposomal vesicles encapsulating rhodanese for cyanide antagonism. Drug Deliv. 2009;16(6):312-9. doi: 10.1080/10717540903003711. PubMed PMID: 19606945.

22. McCarthy C, Dimitrov BD, Meurling IJ, Gunaratnam C, McElvaney NG. The CF-ABLE score: a novel clinical prediction rule for prognosis in patients with cystic fibrosis. Chest.

2013;143(5):1358-64. Epub 2012/11/23. doi: 10.1378/chest.12-2022. PubMed PMID: 23172242.

23. Leber AL. Clinical Microbiology Procedures Handbook, Fourth Edition: American Society of Microbiology; 2016.

24. Bhatt JM. Treatment of pulmonary exacerbations in cystic fibrosis. Eur Respir Rev. 2013;22(129):205-16. Epub 2013/09/03. doi: 10.1183/09059180.00006512. PubMed PMID: 23997047.

25. Lundquist $P$, Sorbo $B$. Rapid determination of toxic cyanide concentrations in blood. Clin Chem. 1989;35(4):617-9. PubMed PMID: 2539272.

26. Jackson R, Oda RP, Bhandari RK, Mahon SB, Brenner M, Rockwood GA, et al.

Development of a fluorescence-based sensor for rapid diagnosis of cyanide exposure. Anal Chem. 2014;86(3):1845-52. Epub 2014/01/05. doi: 10.1021/ac403846s. PubMed PMID: 24383576; PubMed Central PMCID: PMCPMC3983020.

27. Miller MR, Hankinson J, Brusasco V, Burgos F, Casaburi R, Coates A, et al. Standardisation of spirometry. Eur Respir J. 2005;26(2):319-38. Epub 2005/08/02. doi: 10.1183/09031936.05.00034805. PubMed PMID: 16055882.

28. Nam SW, Chen X, Lim J, Kim SH, Kim ST, Cho YH, et al. In vivo fluorescence imaging of bacteriogenic cyanide in the lungs of live mice infected with cystic fibrosis pathogens. PLoS One. 2011;6(7):e21387. Epub 2011/07/14. doi: 10.1371/journal.pone.0021387. PubMed PMID: 21750709 ; PubMed Central PMCID: PMCPMC3131278.

29. Lauridsen RK, Sommer LM, Johansen HK, Rindzevicius T, Molin S, Jelsbak L, et al. SERS detection of the biomarker hydrogen cyanide from Pseudomonas aeruginosa cultures isolated from cystic fibrosis patients. Sci Rep. 2017;7:45264. Epub 2017/03/30. doi: 10.1038/srep45264. PubMed PMID: 28349938; PubMed Central PMCID: PMCPMC5368648. 
30. Aminlari M, Malekhusseini A, Akrami F, Ebrahimnejad HJCCP. Cyanide-metabolizing enzyme rhodanese in human tissues: comparison with domestic animals. 2007;16(1):47-51. doi: 10.1007/s00580-006-0647-x.

31. Thompson JP, Marrs TC. Hydroxocobalamin in cyanide poisoning. Clin Toxicol (Phila). 2012;50(10):875-85. Epub 2012/11/21. doi: 10.3109/15563650.2012.742197. PubMed PMID: 23163594.

32. Moss RB. Fungi in cystic fibrosis and non-cystic fibrosis bronchiectasis. Semin Respir Crit Care Med. 2015;36(2):207-16. Epub 2015/04/01. doi: 10.1055/s-0035-1546750. PubMed PMID: 25826588. 


\section{Figure legends}

Figure 1. Total cyanide concentrations in the sputum samples of our 13 CF patients in acute clinical exacerbation. Mean CN concentration reached $153 \pm 125 \mu \mathrm{M}$. Data from other studies reporting cyanide concentrations in the sputum of CF patients either colonized with pseudomonas $(72 \pm 6.6 \mu \mathrm{M})[5]$ or who presented in the outpatient setting but with no evidence for clinical exacerbation $(37 \pm 6.8 \mu \mathrm{M})$ [19], are also displayed. 


\begin{tabular}{|c|c|c|c|c|c|c|c|c|}
\hline Sample & Age & $\mathrm{FEV}_{1}$ & BMI & CF-ABLE & $\begin{array}{c}\text { Admission } \\
\text { Days in } \\
\text { Previous } \\
\text { Year }\end{array}$ & $\begin{array}{l}\text { Reason } \\
\text { for } \\
\text { Admission }\end{array}$ & $\begin{array}{c}\text { Days of } \\
\text { Admission } \\
\text { until } \\
\text { Collection }\end{array}$ & Sputum Culture \\
\hline 1 & 34 & 30 & 22 & 3.5 & 9 & A, B & 1 & $\begin{array}{c}\text { Burkholderia, } \mathrm{P} \text {. } \\
\text { aeruginosa }\end{array}$ \\
\hline 2 & 26 & 47 & 27 & 3.5 & 10 & $A, B, D$ & 1 & $\begin{array}{l}\text { P. aeruginosa, } \mathrm{H} \text {. } \\
\text { influenzae }\end{array}$ \\
\hline 3 & 35 & 30 & 24 & 3.5 & 19 & $A, B, D$ & 1 & $\begin{array}{l}\text { P. aeruginosa, } \\
\text { Achromobacter } \\
\text { xylosoxidans }\end{array}$ \\
\hline 4 & 24 & 54 & 22 & 0 & 39 & C & 8 & P. aeruginosa \\
\hline 5 & 35 & 62 & 25 & 0 & 9 & B & 1 & $\begin{array}{l}\text { S. aureus, } \mathrm{P} \text {. } \\
\text { aeruginosa }\end{array}$ \\
\hline 6 & 48 & 18 & 16 & 5 & 64 & $B, E$ & 5 & $\begin{array}{l}\text { S. aureus, } \mathrm{P} \text {. } \\
\text { aeruginosa }\end{array}$ \\
\hline 7 & 36 & 66 & 23 & 3.5 & 10 & $A, B, D$ & 1 & P. aeruginosa \\
\hline 8 & 31 & 15 & 13 & 5 & 153 & $A, B$ & 1 & P. aeruginosa \\
\hline 9 & 36 & 31 & 24 & 3.5 & 15 & A, B & 1 & P. aeruginosa \\
\hline 10 & 32 & 22 & 23 & 3.5 & 12 & $B, D, E$ & 1 & P. aeruginosa \\
\hline 11 & 29 & 40 & 26 & 3.5 & 5 & $B, D$ & 2 & P. aeruginosa \\
\hline 12 & 37 & 25 & 23 & 3.5 & 26 & B & 2 & P. aeruginosa \\
\hline 13 & 23 & 54 & 22 & 1 & 14 & B & 1 & $\begin{array}{l}\text { S. aureus, } \\
\text { Achromobacter } \\
\text { xylosoxidans }\end{array}$ \\
\hline
\end{tabular}

Table 1. Sample and subject characteristic data at time of hospital admission. FEV $\mathrm{F}_{1}$ was calculated within 1 day of admission. Sputum cultures obtained at time of admission. Reason for Admission Legend: A - Shortness of breath, B - Increased sputum production, C Hemoptysis, D -Weakness, E - Fever 


\begin{tabular}{|r|r|r|r|}
\hline \multicolumn{1}{|c|}{ Sample } & [Free] & [Total] & $\%$ [Free] \\
\hline 10 & 48.8 & 58.3 & 83.7 \\
\hline 11 & 38.4 & 49.2 & 78 \\
\hline 12 & 43 & 41.6 & 103 \\
\hline 13 & 31.4 & 27 & 116 \\
\hline Mean & $\mathbf{4 0 . 4}$ & $\mathbf{4 4}$ & $\mathbf{9 5}$ \\
\hline SD & $\mathbf{7 . 3}$ & $\mathbf{1 3 . 2}$ & $\mathbf{1 7 . 5}$ \\
\hline
\end{tabular}

Table 2. Sputum Concentrations of free and total CN found in CF sputum using the Cyanalyzer in 4 subjects. 


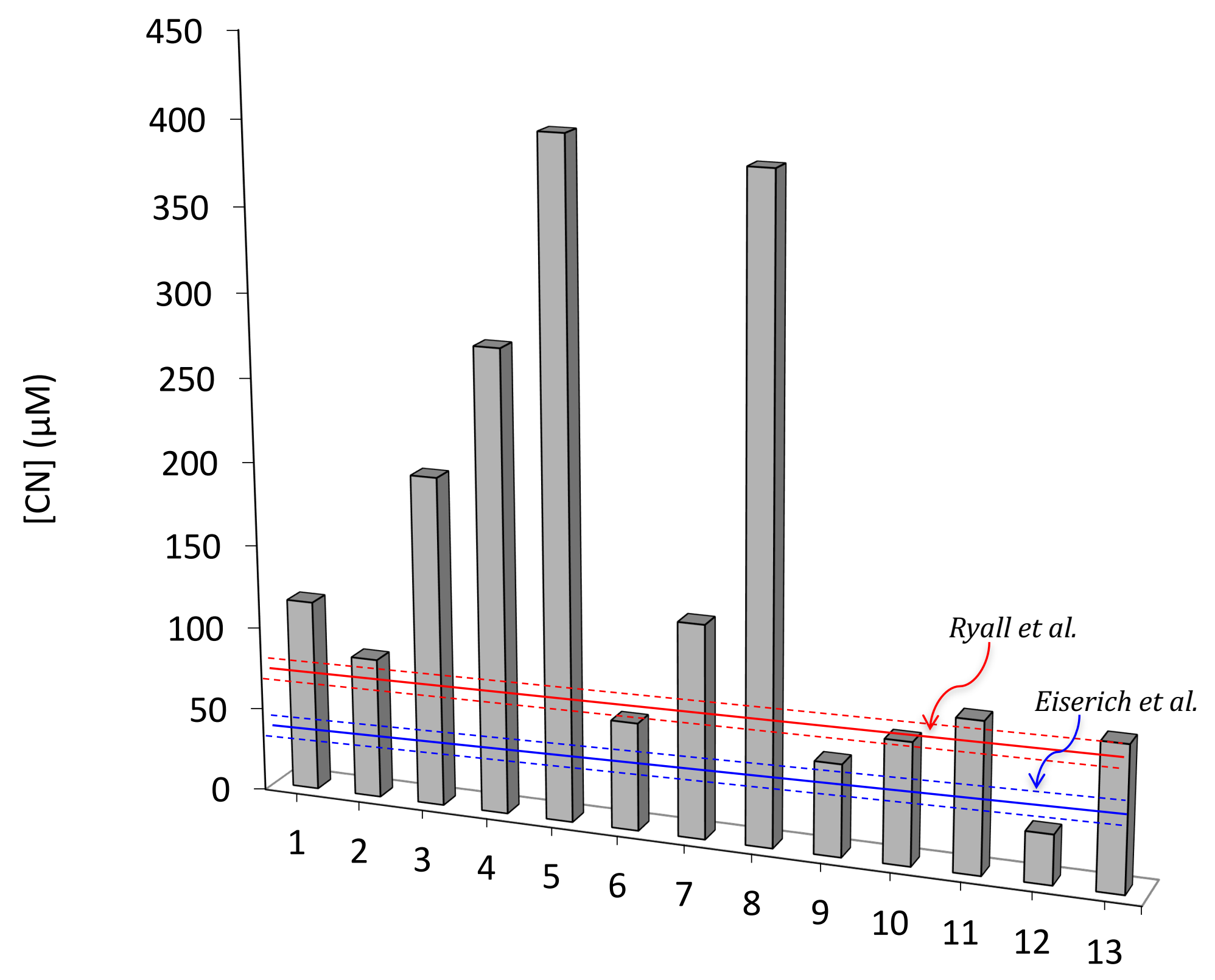

Subject

Figure 1 